\title{
Membangun Sistem Model Learning Style Inventory Untuk Pencapaian Prestasi Belajar Mahasiswa Program E-Learning
}

\author{
${ }^{1}$ Rano Agustino, ${ }^{2}$ Santhi Pertiwi \\ ${ }^{1}$ Sistem Informasi, Fakultas Komputer, Universitas Mohammad Husni Thamrin \\ ${ }^{2}$ PGSD, Fakultas Keguruan dan Ilmu Pendidikan, Universitas Mohammad Husni Thamrin \\ Correspondence author: Rano Agustino, email : rano.agustino@gmail.com
}

DOI: https://doi.org/10.37012/jipmht.v4i2.418

\begin{abstract}
ABSTRAK
Dalam meningkatkan kualitas pendidikan dengan cara mengajar adalah hal yang paling besar efektifitas nya. Karena dengan cara mengajar yang baik dan tepat kemungkinan besar dapat meningkatkan penyerapan pengetahuan bagi pelajar, sehingga kualitas pengetahuan dari pelajar menjadi meningkat. Ada beberapa Teknik untuk meningkatkan kualitas dalam mengajar, salah satu nya adalah dengan mengetahui Gaya Belajar dari siswa tersebut. Metode untuk mengetahui Gaya Belajar seperti Visual Auditorial Kinestetis (VAK), Learning Style Inventory, Myers-Briggs Type Indicator (MBTI) dan yang lain nya, namun pada penelitian ini menggunakan Learning Style Inventory (LSI) yang dikenalkan oleh David Kolb. Untuk melihat Gaya Belajar dari masing masing pelajar maka pada pene;itain ini diadakan kuisioner online. Responden pada penelitian ini adalah mahasiswa onlin di Universitas Mohammad Husni Thamrin Program Studi Teknik Informatika dengan jumlah responden 50 mahasiswa. Dengan menggunakan model Regresi Linear menunjukan nilai Signifikansi yaitu 0.02 dimana lebih kecil dari $5 \%$, maka analisa dapat dilanjutkan. Disisi hasil yang lain, berdasarkan nilai R Square yaitu 0.099 atau 0.1 dimana itu adalah Koefisien Determinasi atau dapat diartikan bahwa Variabel Nilai LSI mempunyai kemampuan mempengaruhi sebesar $10 \%$ pada Variabel Nilai Mahasiswa
\end{abstract}

Kata Kunci : LSI to ERP, Model Sistem LSI, LSI dengan Linear Regresi

\begin{abstract}
In improving the quality of education by teaching, it is the thing that has the greatest effectiveness.Because with a good and appropriate teaching method it is likely to increase the absorption of knowledge for students, so that the quality of knowledge from students increases. There are several ways to improve the quality of teaching, one of which is to know the learning styles of these students. Methods to determine learning styles such as Visual Auditorial Kinesthetic (VAK), Learning Style Inventory, Myers-Briggs Type Indicator (MBTI) and others, but in this study using the Learning Style Inventory (LSI) introduced by David Kolb. To see the Learning Style of each student, an online questionnaire was held. Respondents in this study were online students of the Mohammad Husni Thamrin University Informatics Engineering Study Program with 50 students as respondents. By using the Linear Regression model, it shows a significance value of 0.02 which is less than 5\%, so the analysis can be
\end{abstract}


continued. On the other hand, the results are based on the value of R Square, which is 0.099 or 0.1, where it is the Coefficient of Determination or it can be interpreted that the LSI Value Variable has the ability to influence $10 \%$ of the Student Value Variable.

Keyword : LSI to ERP, Model Sistem LSI, LSI dengan Linear Regresi

\section{PENDAHULUAN}

Perkembangan pendidikan dan teknologi informasi pada saat ini sangat dibutuhkan untuk memecahkan masalah dalam mencerdaskan kehidupan manusia. Beberapa usaha dan cara yang dilakukan oleh setiap institusi atau lembaga pendidikan untuk mendapatkan pengetahuan yang baik yang dapat meningkatkan kualitas pendidikannya agar pelajar dapat menyerap ilmu yang sedang dipelajari nya. Terkait dengan masalah ini kami peneliti akan mencoba memecahkan permasalahan pendidikan ini dengan menggunakan gaya belajar atau Learning Style Inventory (LSI). LSI sendiri merupakan pengembangan diri yang bertujuan untuk membantu pelajar atau individu untuk mengetahui gaya belajar mereka sendiri sehingga dengan mengetahui gaya belajar mereka sendiri diharapkan dapat memaksimalkan kemampuan belajar mereka. LSI itu sendiri memiliki beberapa tipe kategori, namun pada penelitian ini kami akan menggunakan tipe kategori yang ditemukan oleh david kolb dimana diantaranya adalah diverging, assimilating, coverging dan accomodating (Kolb, D. A. 2007). Bisa dilhat pada Gambar 1. LSI Kolb's.

\section{Learning Cycle \& Styles overlay (Source: David Kolb)}

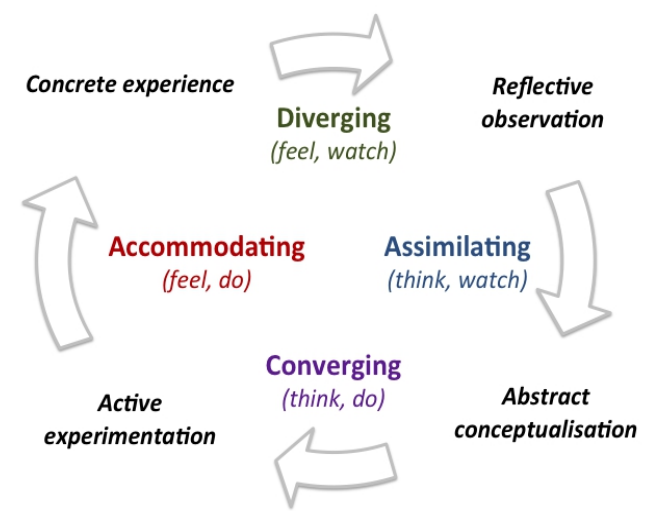

\section{Gambar 1. LSI Kolbs}

Penelitian ini pada awal nya akan membuat aplikasi Kusioner Learning Style Inventory berbasis web sebagai sarana untuk menyediakan form input data kuisioner yang akan di isi oleh mahasiswa (dalam penelitian ini responden). Populasi dari responden yang akan di teliti 
adalah mahasiswa online learning Program Studi Teknik Informatika semester satu di Universitas Mohammad Husni Thamrin Jakarta yang mana telah bekerja sama dengan HARUKAEDU dalam pembelajaran e-learning. Hasil data dari kuisioner tersebut akan menentukan jenis kategori dari empat tipe LSI Kolb, yaitu; diverger merupakan kombinasi dari perasaan dan pengamatan. assimilator merupakan kombinasi dari berpikir dan mengamati. konverger merupakan kombinasi dari berpikir dan berbuat. accomodator merupakan kombinasi dari perasaan dan tindakan (Kolb, A. Y, et all. 2014 ).

Setelah data hasil kuisioner sudah terkumpul maka akan di uji korelasi dengan nilai akademis mahasiswa. Untuk model yang digunakan dengan menggunakan LR (Linear Regression) untuk mengukur apakah hasilnya memiliki perberdaan yang signifikansi antara data kuisioner dalam hal ini disebut dataset LSI dengan nilai akademis mahasiswa. Dari hasil kuisioner dan olah data nanti akan merekomendasikan gaya mengajar apa yang sesuai dengan gaya belajar mahasiswa online learning pada mahasiswa Universitas Mohammad Husni Thamrin. Gaya mengajar ini juga memiliki 4 tipe yang sama dengan 4 tipe gaya belajar dari kolb, gaya mengajar yang digunakan adalah Kolb Educator Role Profile (KERP) (Kolb, A. Y, et all. 2014), bisa dilihat pada Gambar 2. KERP.

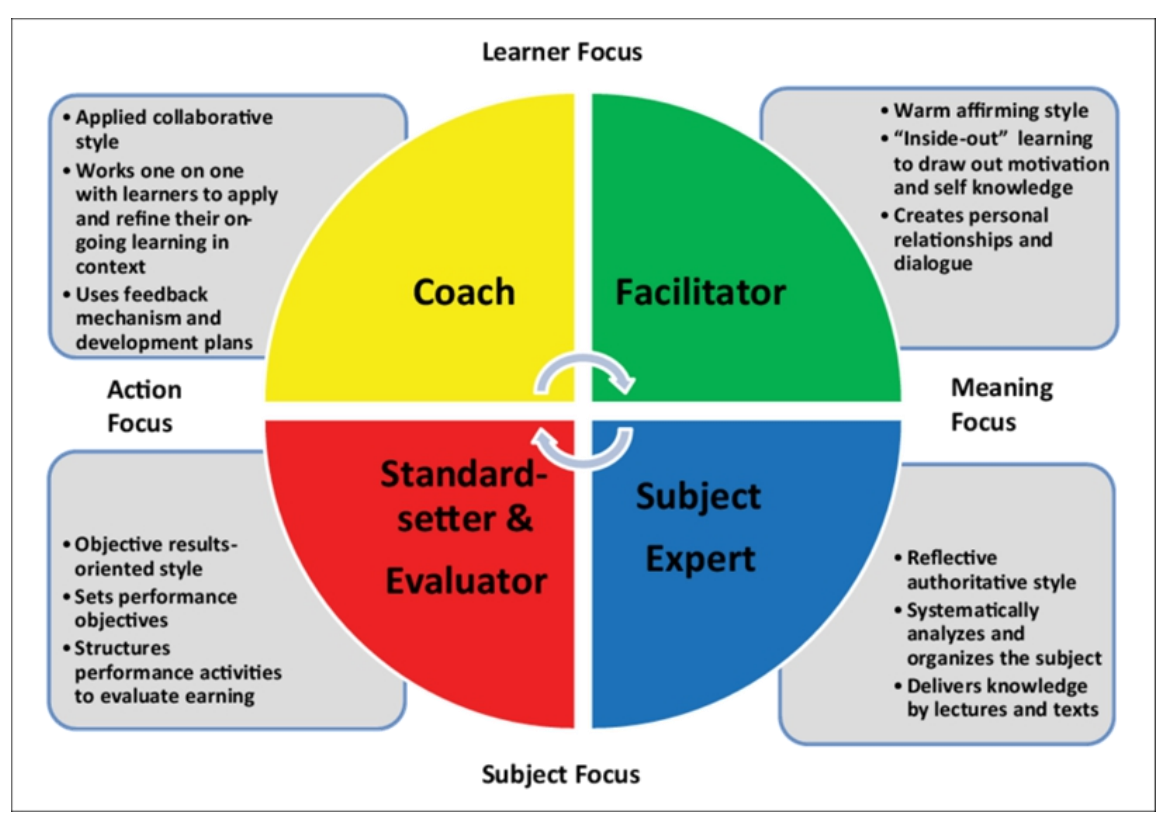

Gambar 2. KERP

\section{METODOLOGI}

Pada penelitian ini menggunakan Metode Kuantitatif dimana data yang digunakan adalah Data Primer yang berasal dari database aplikasi kuesioner LSI yang beralamat di 
http:/quisionerano.com/ . sedangkan Metode Pendekatan Sistem nya menggunakan Metode System Development Life Cycle (SDLC), yang mana menggunakan model Waterfall (Agustino, R. et al, 2020). Bisa dilihat pada Gambar 3. Model Waterfall untuk lebih jelasnya.

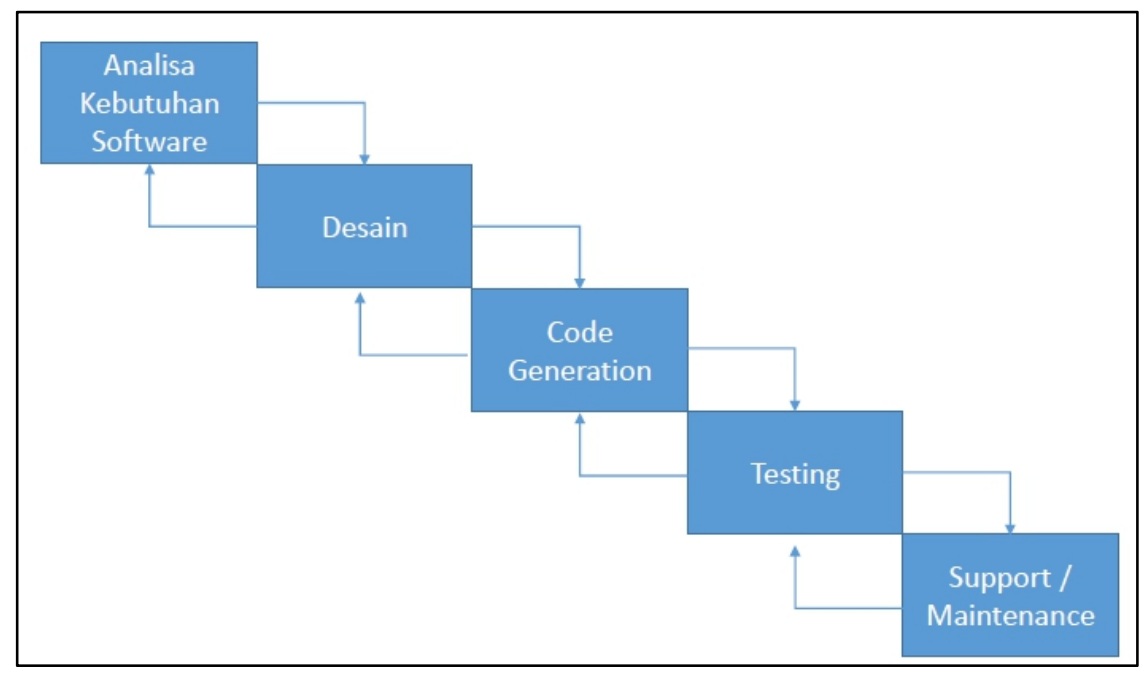

Gambar 3. Model Waterfall

Adapun tahapan model waterfall pada penelitian ini yaitu ;

1. Analisa Kebutuhan Software

Pada tahap awal ini peneliti mengadakan Focus Group Discussion pada mitra untuk berdiskusi tentang kebutuhan sistem yang akan digunakan pada aplikasi kuisioner LSI.

2. Desain

Setelah tahap kebutuhan software sudah dilakukan maka akan masuk pada tahap desain aplikasi. Ini dilakukan agar aplikasi kuisioner ini nanti nya sesuai dengan kebutuhan penelitan. Pada tahap ini juga sering disebut Mockup dan Rancangan User Interface.

3. Code Generation

Pada tahap ini adalah tahap pembuatan program dengan bahasa pemrograman. Aplikasi LSI ini adalah aplikasi berbasis web, maka peneliti menentukan bahasa pemrograman yang digunakan adalah PHP dan untuk database nya meggunakan MySQL.

4. Testing 
Pada tahap ini dilakukan setelah program sudah selesai dibuat oleh programer, testing ini dilakukan oleh Mitra, Peneliti dan Programer. Testing ini menggunakan White Box dan Black Box testing untuk mengukur kelayakan program aplikasi LSI ini.

5. Support / Maintenance

Pada tahap ini dilakukan setelah tahap testing selesai. Pada tahap ini dilakukan untuk memantau apakah aplikasi berjalan lancar ketika digunakan pada saat responden menginput kuisioner.

Kuisioner LSI dilaksanakan pada tanggal 30 Agustus 2020 diikuti oleh 50 Responden. Setelah 50 responden sudah dilakukan maka dilanjutkan dengan pengambilan data pada aplikasi LSI. Setelah data sudah didapat maka akan integrasikan dengan data nilai persemester dari mahasiswa yang mengikuti (Responden). Pada Gambar 4. Poses Integrasi, menjelaskan tentang proses integrasi data nya.

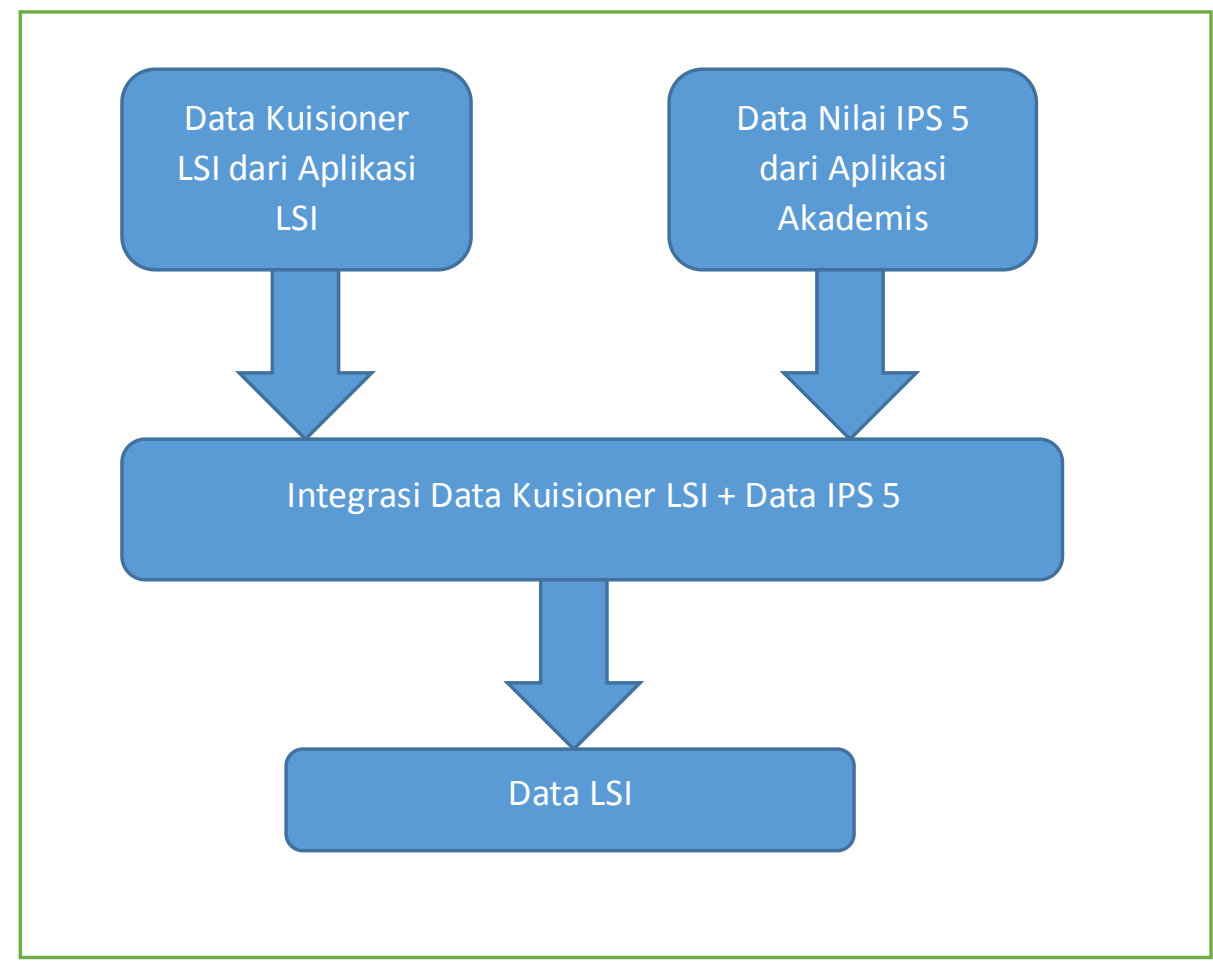

Gambar 4. Proses Integrasi 


\section{HASIL DAN TEMUAN}

\section{A.HASIL}

Setelah Data LSI selesai diintegrasi maka untuk menentukan Nilai Independen (variabel X) yang mempengaruhi Nilai Dependen (Variabel Y) dengan tujuan agar bisa diolah menggunakan Regresi Linear. Pada penelitian ini Variabel X adalah data hasil LSI yang berasal dari Aplikasi Kuisioner yang mempengaruhi Variabel Y dalam hal ini adalah data Nilai Mahasiswa.

Setelah data selesai di integrasi maka data akan di olah dan di analisis oleh Regresi Linear, berikut ini adalah hasil data nya.;

ANOVA

\begin{tabular}{|c|c|c|c|c|c|}
\hline & $d f$ & $S S$ & $M S$ & $F$ & $\begin{array}{c}\text { Significance } \\
F\end{array}$ \\
\hline Regression & 1 & 1,149159875 & 1,14916 & 5,296359 & 0,02575467 \\
\hline Residual & 48 & 10,41464012 & 0,216972 & & \\
\hline Total & 49 & 11,5638 & & & \\
\hline
\end{tabular}

Tabel 1. Anova

Dari Tabel 1. Anova menjelaskan hasil dari Significance F yaitu 0.025 dimana $<0.05$ dimana dapat disimpulkan bahwa nilai data yang dihasilkan memadai dan dapat dilanjutkan untuk di analisa.

\section{SUMMARY OUTPUT}

\section{Regression Statistics}

\begin{tabular}{lr}
\hline Multiple R & 0,315239 \\
\hline R Square & 0,099375627 \\
\hline $\begin{array}{l}\text { Adjusted R } \\
\text { Square }\end{array}$ & 0,080612619 \\
\hline Standard Error & 0,465802178 \\
\hline Observations & 50
\end{tabular}

Berdasarkan nilai $\mathrm{R}$ Square $=0.099$ atau bisa dibulatkan menjadi 0.1 dimana menyatakan bahwa Koefisien Determinasi atau dapat diartikan bahwa Variabel X (Nilai LSI) mempunyai kemampuan mempengaruhi sebesar $10 \%$ pada Variabel Y (Nilai Mahasiswa). Dan nilai Standar Error $=0.4$ dimana dapat diartikan bahwa kemungkinan kesalahan Variabel $\mathrm{X}$ dalam mempengaruhi Variabel Y sebesar $40 \%$. 
Setelah mengetahui bahwa Gaya Belajar atau Nilai LSI berpengaruh terhadap Nilai Mahasiswa maka peneliti akan menjelaskan hasil dari data kuisioner dan nilai mahasiswa. Pada Gambar 5. Rata Rata Nilai Mahasiswa, menjelaskan bahwa Gaya belajar Accomodating mendapatkan hasil nilai $29 \%$ dari 50 Mahasiswa yang menjadi responden. Sedangkan Gaya Belajar Diverging mendapatkan nilai rata rata $19 \%$, lalu Gaya Belajar Assimilating mendapati $26 \%$ dan Gaya Belajar Converging mendapati 26 \%. Dapat di simpulkan bahwa nilai tertinggi didapati dari Mahasiswa yang memiliki Gaya Belajar Accomodating yaitu sebesar 29 \% sedangkan yang terendah adalah yang memiliki Gaya Belajar Diverging yaitu sebesar $19 \%$.

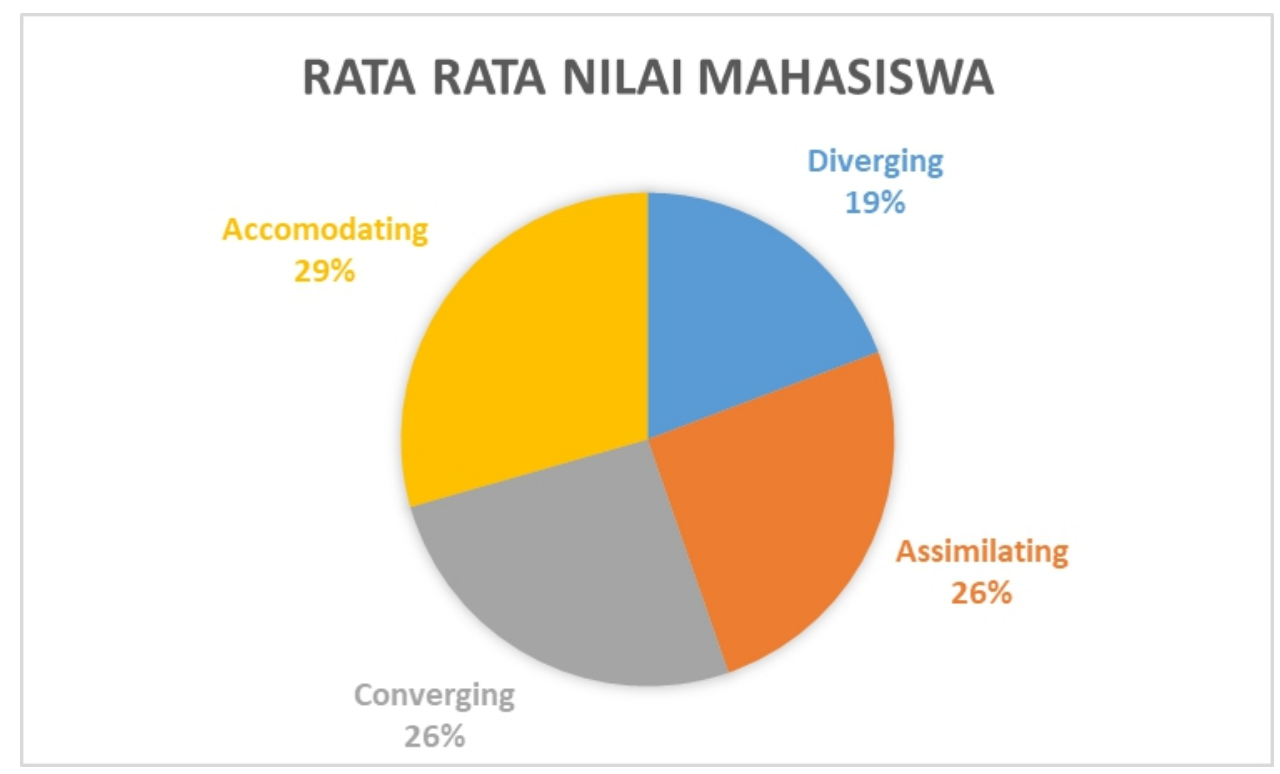

Gambar 5. Rata Rata Nilai Mahasiswa 


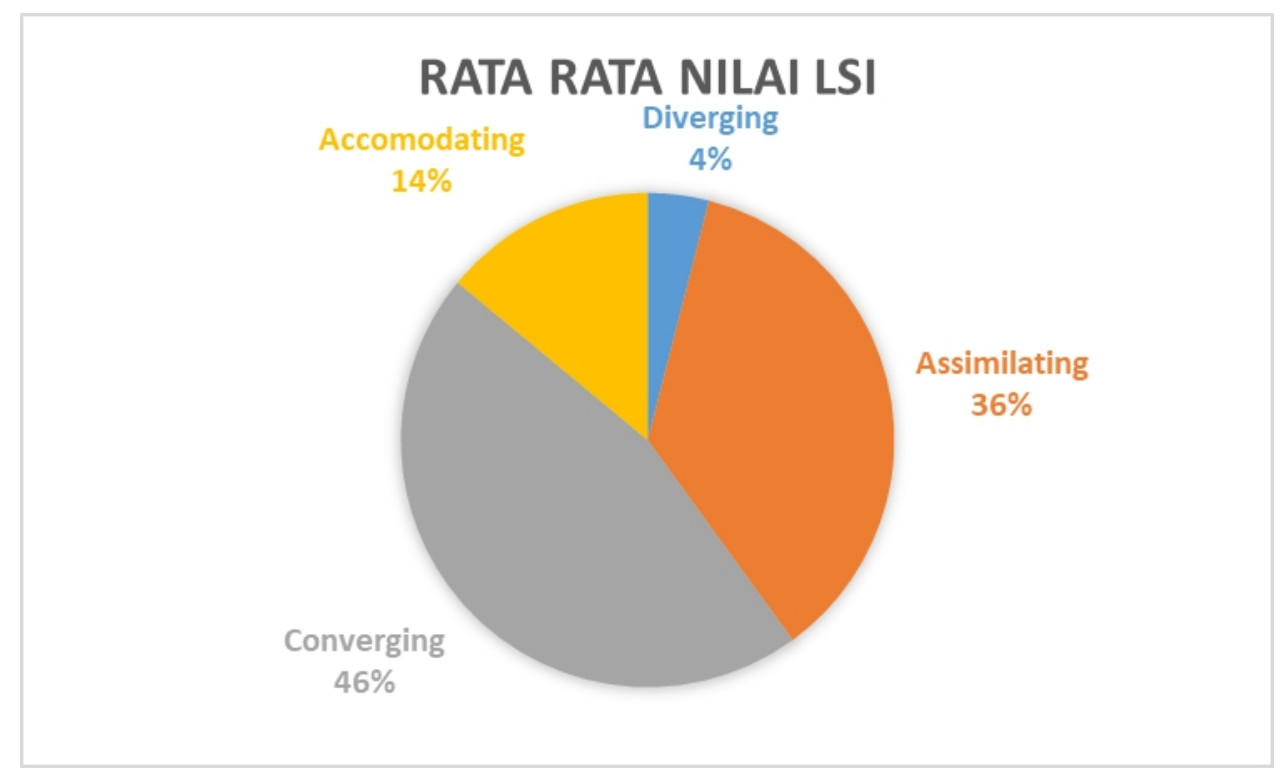

Gambar 6. Rata Rata Nilai LSI

Pada Gambar 6. Rata Rata Nilai LSI, menjelaskan bahwa dari 50 mahasiswa yang menjadi responden yang memiliki Gaya Belajar Diverging sebanyak 4\% dan yang mempunyai Gaya Belajar Assimilating sebanyak $36 \%$, lalu Gaya Belajar Converging sebanyak $46 \%$ dan Gaya Belajar Accomodating sebanyak $14 \%$. Berdasarkan data tersebut dapat disimpulkan bahwa dari 50 responden yang mengikuti kuisioner Gaya Belajar Converging yang paling banyak yaitu sebesar $46 \%$ atau sebanyak 23 responden, dan yang paling sedikit yang memilki Gaya Belajar Diverging yaitu sebesar $4 \%$ atau sebanyak 2 responden.

\section{B. TEMUAN}

Pada penelitian ini pengklasifikasian Gaya Belajar menggunakan Learning Style Inventory dari David Kolb, dimana didapati beberapa temuan pengetahuan tentang kecenderungan gaya belajar dari mahasiswa online learning pada Fakultas Komputer di Universitas Mohammad Husni Thamrin. Dari hasil tersebut dapat di sesuaikan dengan Gaya Mengajar yang terdapat pada model Kolb Educator Role Profile dari David Kolb, seperti pada Gambar 3. KERP, menjelaskan 4 model Gaya Mengajar yang berhubungan dengan Gaya Belajar LSI.

Misal nya pada penelitian ini Nilai LSI yang paling tinggi dari mahasiswa yang memiliki Gaya Belajar Converging maka Gaya Mengajar yang sesuai jika ingin melihat yang paling banyak mahasiswa nya adalah menggunakan Gaya Mengajar Evaluator Role yaitu mengajar dengan cara menerapkan keterampilan dalam memecahkan suatu pekerjaan yang dianggap pekerjaan itu penting. Misal nya apakah keterampilan itu memenuhi kriteria trend pekerjaan 
saat ini. Jika tidak diperlukan maka mahasiwa yang memiliki Gaya Belajar Converging ini akan malas, namun sebalik nya jika keterampilan ini diperlukan maka mereka akan meningkatkan kemampuan mereka. Berikut ini adalah Gambar 7. Penyesuaian LSI dengan ERP, untuk menjelaskan tentang penyesuaian gaya belajar dengan gaya mengajar berdasarkan David Kolb.

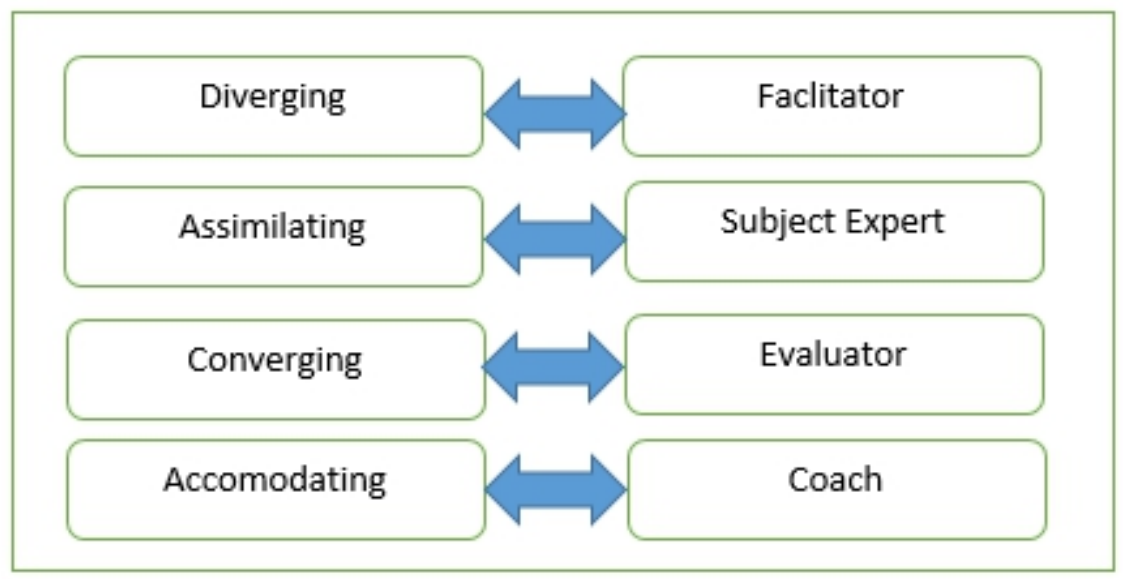

Gambar 7. Penyesuaian LSI dengan ERP

Penelitian yang pernah dilakukan di Kampus Bina Sarana Informatika pada Program Studi Manajemen Administrasi semester empat yang berlokasi di Jatiwaringin (Sukmana, 2017). Pada penelitian ini menggunakan Metode LSI dari David Kolb, dimana langkah langkah yang dilakukan terdiri dari Mengidentifikasi Masalah, Studi Literatur, Desain Quisioner dilanjutkan dengan Validasi Pertanyaan sampai dengan Analisa dan Kesimpulan. Responden pada penelitian ini sebanyak 127 Mahasiswa tetapi data yang valid sebanyak 111 data. Dari 111 data, responden berjenis kelamin perempuan sebanyak 93 sedangkan pria hanya sebanyak 18. Peneliti pada penelitian ini mengukur Model LSI dengan kecenderungan seperti ; Tindakan, Pemikir, Pengamat dan Perasa, dan mayoritas responden memiliki Kecenderungan Tindakan yaitu sebanyak 50 responden atau sebesar $50 \%$. Sedangkan pegukuran dengan Gaya Belajar yang paling banyak dimiliki adlah Gaya Belajar Divergen yaitu sebanyak 43 responden atau sebesar $39 \%$ dari 111 responden.

Di penelitian lain nya, pernah dilakukan di Universitas Bung Hatta pada Program Studi Pendidikan Matematika selama empat tahun dari tahun 2012 sampai dengan 2015 (Wahyuni, Y. 2017). Peneliti mengidentifikasi Gaya Belajar dengan menggunakan model Visual Auditorial Kinestik (VAK). Dalam pengambilan sample peneliti menggunakan teknik Purposive Sampling dengan instrument yang digunakan dengan cara kuisioner. Pada 
penelitian ini menghasilkan data Gaya Belajar yang beragam tiap tahun nya, pada tahun 2012 di dominasi oleh Auditorial sebanyak 50 \%, sedangkan pada tahun 2013 di dominasi oleh Auditorial sama seperti tahun 2012 sebelum nya, namun jumlah nya berbeda yaitu sebesar $45 \%$, dilanjutkan pada tahun selanjut nya yaitu tahun 2014 masih gaya belajar Auditorial yang berdominasi yaitu sebesar $50 \%$. Sedangkan pada tahun 2015 mengalami perbedan dengan tahun tahun sebelum nya karena Gaya Belajar di dominasi oleh Gaya Belajar Visual $50 \%$.

Pada penelitian yang lain pada tahun 2020 yang dilakukan di institusi pendidikan di Oman (Syahrin, S., \& Salih, A. A., 2020). Responden pada penelitian ini adalah siswa yang mengikuti pembelajaran online dengan menggunaka platform e-learning ketika dalam kondisi Pandemik. Pada penelitian ini mencoba menganalisa tentang kesukaan siswa pada Gaya Belajar Online terhadap aplikasi teknologi platform e-learning yang mereka gunakan. Hasil dari analisa yang dilakukan peneliti menghasilkan kesimpulan bahwa Gaya Belajar Konvergen mendapati $53 \%$. Gaya Belajar Diverging mendapati jumlah yang paling sedikit yaitu sebesar 6,3 \%. Pada tahap uji data menggunakan Chi-Square dan menghasilkan PValue sebesar 0.021 yang mana ini kurang dari $5 \%$ dari nilai signifikansi. Sedangkan nilai r yang didapat sebesar 0.78 dimana ini menyatakan adanya hubungan koorelasi antara platform yang digunakan dengan Gaya Belajar yang mereka miliki.

Sedangkan pada penelitian yang lain yang dilakukan di Sekolah MAN II Yogyakarta tahun ajaran 2016/2017 (). Responden pada penelitian ini adalah siswa dari Kota Yogyakarta yang berjumlah 322 Responden, yang terdiri dari 52 Responden berasal dari MAN II Yogyakarta dan 270 Responden berasal dari 6 Sekolah di sekitar yogyakarta. Hasil olah data yang didapati menjelaskan bahwa responden yang berasal dari MAN II Yogyakarta cendrung memiliki Gaya Belajar Assimilator sebesar 36,5 \% dari 52 Responden yaitu sebanyak 19 Responden, dan yang paling sedikit memiliki Gaya Belajar Accomodator sebesar 19,6 \% yaitu sebanyak 6 Peserta. Sedangkan hasil dari 6 Sekolah yang lain Gaya Belajar yang paling tinggi dimiliki oleh Gaya Belajar Assimilator yaitu sebesar 35,5 \% dari 270 Responden yaitu sebanyak 96, dan Gaya Belajar yang paling sedikit adalah Gaya Belajar Accomodator sebesar 10,3 \% yaitu sebanyak 28 Peserta. Dipenelitian ini menyimpulkan bahwa terdapat hubungan antara kemampuan spasial dengan Gaya Belajar. 


\section{KESIMPULAN \& SARAN}

\section{A. KESIMPULAN}

Setelah diketahui Gaya Belajar LSI yang dimiliki dari masing masing pelajar, maka diharapkan dapat di ketahui Gaya Mengajar ERP yang sesuai dengan LSI yang dimiliki pelajar tersebut. Hasil olah data dari penelitian ini telah menjelaskan bahwa dari 50 responden paling terbanyak memiliki Gaya Belajar Converging sebesar $46 \%$ atau sebanyak 23 responden. Gaya Mengajar ERP yang sesuai dengan Gaya Belajar Converging adalah Evaluator jika tujuan nya adalah agar dapat di terapkan Gaya Mengajar kebanyak siswa. Namun jika ingin membangun mahasiswa yang nilai nya rendah ke yang lebih baik maka bisa dilihat Nilai Mahasiswa yang paling terendah yaitu mahasiswa yang memiliki Gaya Belajar Diverging yaitu sebesar 19 \%, maka Gaya Mengajar ERP yang sesuai dengan Gaya Belajar Diverging adalah Facilitator (Gambar 7. Penyesuaian LSI dengan ERP).

\section{B. SARAN}

Peneliti mempunyai beberapa saran untuk penelitian ini, diantaranya :

1. Diharapkan penelitian nanti nya dapat memprediksi nilai mahasiswa dan gaya belajar LSI dengan beberapa variabel pendukung nya dengan menggunakan beberapa Algoritma, misal nya C.45, Naive Bayes, Neural Network atau yang lain nya.

2. Diharapkan penelitian lain nya juga dapat melakukan analisa data yang lebih luas lagi cakupan nya. Misal nya populasi di perluas lagi menjadi perdaerah atau peribukota, karena media untuk kuisioner ini sudah menggunakan aplikasi berbasis web sehingga bisa dilakukan dimana saja

3. Diharapkan dipenelitian kedepannya bisa ditambah dengan beberapa model pengukuran gaya belajar seperti Visual Auditorial Kinestesis (VAK), Myers-Birggs Type Indicator (MBTI) atau dengan Gaya Belajar lain nya.

\section{TERIMA KASIH}

Terima kasih kepada Direktorat Riset dan Pengabdian Masyarakat Deputi Bidang Penguatan Riset dan Pengembangan atas pendanaan nya. 


\section{Referensi}

1. Agustino, R., Widodo, Y. B., Wiyatno, A., \& Saputro, M. I. (2020). Sistem Informasi Penelitian dan Pengabdian Masyarakat di Universitas Mohammad Husni Thamrin. Jurnal Jaring SainTek, 2(1), 1-12.

2. Kolb, D. A. (2007). The Kolb learning style inventory. Boston, MA: Hay Resources Direct.

3. Kolb, A. Y., Kolb, D. A., Passarelli, A., \& Sharma, G. (2014). On becoming an experiential educator: The educator role profile. Simulation \& gaming, 45(2), 204-234.

4. Melinda, G., \& Wisudawati, A. W. (2018). IDENTIFIKASI GAYA BELAJAR MODEL KOLB TERHADAP PESERTA DIDIK MAN II YOGYAKARTA.

5. Sukmana, S. H. (2017). Analisa Kecenderungan Dan Jenis Gaya Belajar Menggunakan Metode Learning Style Inventory (Lsi). Jurnal Pilar Nusa Mandiri, 13(2), 175-180.

6. Wahyuni, Y. (2017). Identifikasi Gaya Belajar (Visual, Auditorial, Kinestetik) Mahasiswa Pendidikan Matematika Universitas Bung Hatta. JPPM (Jurnal Penelitian dan Pembelajaran Matematika), 10

7. Quillin III, R. C., Cortez, A. R., Pritts, T. A., Hanseman, D. J., Edwards, M. J., \& Davis, B. R. (2016). Surgical resident learning styles have changed with work hours. Journal of Surgical Research, 200(1), 39-45. 